\title{
Fabrication of a nonenzymatic cholesterol biosensor using carbon nanotubes from coconut oil
}

\author{
Mitali Saha $\cdot$ Soma Das
}

Received: 29 January 2014/ Accepted: 20 February 2014/Published online: 15 March 2014

(C) The Author(s) 2014. This article is published with open access at Springerlink.com

\begin{abstract}
A nonenzymatic cholesterol biosensor was fabricated at the surface of carbon nanotube electrode (CCNT), obtained from coconut oil. The voltammetric behavior of cholesterol at CCNT electrode was investigated by cyclic voltammetry and differential pulse voltammetry in the presence of $0.001 \mathrm{M} \mathrm{H}_{2} \mathrm{SO}_{4}$ as electrolyte. The influence of the experimental parameters on the peak currents of cholesterol like $\mathrm{pH}$, accumulation time, and scan rates were optimized. Under optimum conditions, the peak current was found to be linear in the cholesterol concentration range from 1 to $50 \mu \mathrm{M}$ with a sensitivity of $\sim 15.31 \pm 0.01 \mu \mathrm{A} \mu \mathrm{M}^{-1} \mathrm{~cm}^{-2}$ and response time of about $6 \mathrm{~s}$. Some characteristic studies of the nonenzymatic biosensor, such as reproducibility, substrate specificity, and storage stability have also been studied.
\end{abstract}

Keywords Carbon nanotube - Cholesterol ·

Nonenzymatic $\cdot$ Cyclic voltammetry $\cdot$ Differential pulse voltammetry

\section{Introduction}

Cholesterol has aroused considerable interest in recent years on account of its being an important parameter in clinical diagnosis. Almost all membranes contain varying level of cholesterol and the level changes during different physiological conditions [1]. There is a strong positive

\footnotetext{
M. Saha $\cdot$ S. Das $(\bowtie)$

Department of Chemistry, National Institute of Technology, Agartala 799055, Tripura, India

e-mail: somachem17@gmail.com

M. Saha

e-mail: mitalichem71@gmail.com
}

correlation between high serum cholesterol level and arteriosclerosis, hypertension, and myocardial infarction. As biosensors have the ability to measure constantly the presence, absence, or concentration of specific organic or inorganic substances in desired test specimens, the thrust to monitor cholesterol in blood is driving the need for the development of efficient cholesterol biosensors to improve the life quality $[2,3]$.

Enzyme-based electrochemical biosensors have shown high selectivity and excellent sensitivity [4-6], but the enzyme is easily denatured during its immobilization procedure and its activity is also affected by temperature, $\mathrm{pH}$, and toxic chemicals. Besides, the reproducibility of enzyme-based sensors is not very good [7] which further restrict the application of cholesterol biosensor. In recent years, nonenzymatic cholesterol sensors have been designed and fabricated to overcome the disadvantages of enzymatic cholesterol sensors.

The cholesterol biosensors based on carbon nanotube (CNT) have been continuously reported [8-17]. It has been demonstrated that carbon nanotubes could promote electron transfer with various redox active proteins, ranging from cytochrome $c$ to glucose oxidase with a deeply embedded redox center and horseradish peroxidase with surface redox centers. To make use of carbon nanotubes in biosensing applications, the ability to immobilize biomolecules on the carbon nanotube structure, without diminishing their bioactivity is indispensable. Therefore, different types of physicochemical approaches have recently been devised for functionalization of carbon nanotubes with biomolecules. Many biological species, such as DNA, proteins and enzymes, have been immobilized on to carbon nanotubes either on their sidewalls or at the end caps. Lee et al. [8] developed a layer-by-layer assembled CNT network as a matrix for loading platinum 
nanoparticles to accomplish the nonenzymatic determination of cholesterol. The sensor with 24 bilayer of CNT shows very low detection limit and a wide linear range from 0.005 to $10 \mathrm{mM}$ with a sensitivity of $8.7 \mu \mathrm{A} \mathrm{mM}^{-1} \mathrm{~cm}^{-2}$. Guo et al. [11] fabricated an amperometric cholesterol biosensor based on layer-by-layer deposition of a cationic polyelectrolyte poly (diallyl dimethyl ammonium chloride) and cholesterol oxidase (ChOx) on multiwalled carbon nanotubes modified gold electrode. A linear range up to $6.0 \mathrm{mM}$ has been observed for the biosensor with a detection limit of $0.2 \mathrm{mM}$.

$\mathrm{Li}$ et al. [12] studied the effect of electron transfer and response current of carbon nanotube modified screen printed electrode for monitoring total cholesterol in blood using cholesterol esterase, cholesterol oxidase, peroxidase, and potassium ferrocyanide. Tan et al. [13] designed an amperometric cholesterol biosensor based on sol-gel chitosan/silica and multiwalled carbon nanotubes, which was used to estimate free cholesterol concentration in real human blood samples. However, these reported biosensors were witnessed by the narrow linear range, low sensitivity and unsatisfactory stability.

Since we have synthesized carbon nanotubes (CCNT) from coconut oil by our own indigenous method and it has also worked as glucose biosensor [18], it was felt to fabricate a new cholesterol biosensor based on this CCNT to check its sensitivity and detection limit towards cholesterol. Hence, in continuation of our earlier work on the synthesis and applications of nanomaterials [18-22], we have now reported a nonenzymatic cholesterol biosensor at carbon nanotube (CCNT) modified electrode. Interestingly, the fabricated sensor showed a high sensitivity of $\sim 15.31 \pm 0.01 \mu \mathrm{A} \mu \mathrm{M}^{-1} \mathrm{~cm}^{-2}$ with the lower detection limit of $0.01708 \mu \mathrm{M}$ in case of cholesterol. In literature many cholesterol sensors based on CNT electrodes have been reported, but synthesis of CNT from a readily available, cheap raw material and its use in cholesterol sensing is quite interesting and it reveals a new direction in research on biosensors.

\section{Experimental}

Reagents and apparatus

Coconut oil of edible quality was used for the synthesis. Cholesterol was purchased from E. Merck. All solutions were prepared with deionized water. The structure and morphology of CCNT were characterized by a scanning electron microscope (Zeiss EVO 50, India) and XRD were recorded with JSO ISO DEBYEFLEX 2002 Model X-ray powder diffractometer. Raman spectra was recorded using a Raman spectrometer; WITEC MODEL with $514 \mathrm{~nm}$ excitation. Electrochemical studies were performed using a mini potentiostat (Dropsens $\mu$ stat 100, Spain).

\section{Synthesis of CCNT}

CCNT was synthesized by a low cost and easy method from coconut oil of edible quality as reported in our earlier paper [18]. It was functionalized using $2 \mathrm{M} \mathrm{HNO}_{3}$, washed and dried. Excess nitrate was removed and complete removal of nitrate was confirmed by Griess's test [23]. The powdered CCNT was then characterized by SEM and XRD.

\section{Fabrication of CCNT electrode}

New modified electrode was designed like the commercially available standard electrode DS110CNT. In case of standard DS110CNT electrode, working electrode was made of functionalized carbon nanotubes, counter electrode was made of carbon, whereas reference electrode and electric contacts were made of silver. In our case, both working and counter electrode were made of CCNT and it was fabricated on an insulating teflon material containing three silver wires, following our reported method [18, 19]. For this, CCNT was first stirred with polystyrene solution, prepared in chloroform (9:1 ratio) followed by sonication. A drop of the slurry was then deposited as a very fine thin film on the teflon substrate covering two silver wires, serving as working and counter electrodes. The third silver wire was used as a reference electrode. The electrode has a dimension of $3.5 \times 1.0 \times 0.5 \mathrm{~cm} \quad$ (length $\times$ width $\times$ height) and it was ideal for working with $50 \mu \mathrm{L}$ volume like the standard electrode.

Nonenzymatic detection of cholesterol with fabricated CCNT electrode

For nonenzymatic detection of cholesterol, CV and DPV studies with various concentrations of cholesterol solutions were performed using $0.001 \mathrm{M} \mathrm{H}_{2} \mathrm{SO}_{4}$ as supporting electrolyte, at modified CCNT electrode. To carry out the electrochemical detection, different concentrations of cholesterol solutions were prepared by dissolving required amount of cholesterol directly into the solution of $0.001 \mathrm{M}$ $\mathrm{H}_{2} \mathrm{SO}_{4}$, maintaining the $\mathrm{pH} \sim 5.3$. Then, $50 \mu \mathrm{L}$ of the cholesterol solution was taken by micropipette and dropped on the surface of electrode. The measurement conditions maintained for $\mathrm{CV}$ were $E$ step $=0.005 \mathrm{~V}, E$ cond $=$ $-0.6 \mathrm{~V}, E$ dep $=-0.5 \mathrm{~V}$, whereas $E$ step $=0.005 \mathrm{~V}$, $E$ pulse $=0.007 \mathrm{~V}, E$ cond $=-0.6 \mathrm{~V}, E$ dep $=-0.5 \mathrm{~V}$, $t$ pulse $=0.07 \mathrm{~V}$ for DPV studies. 


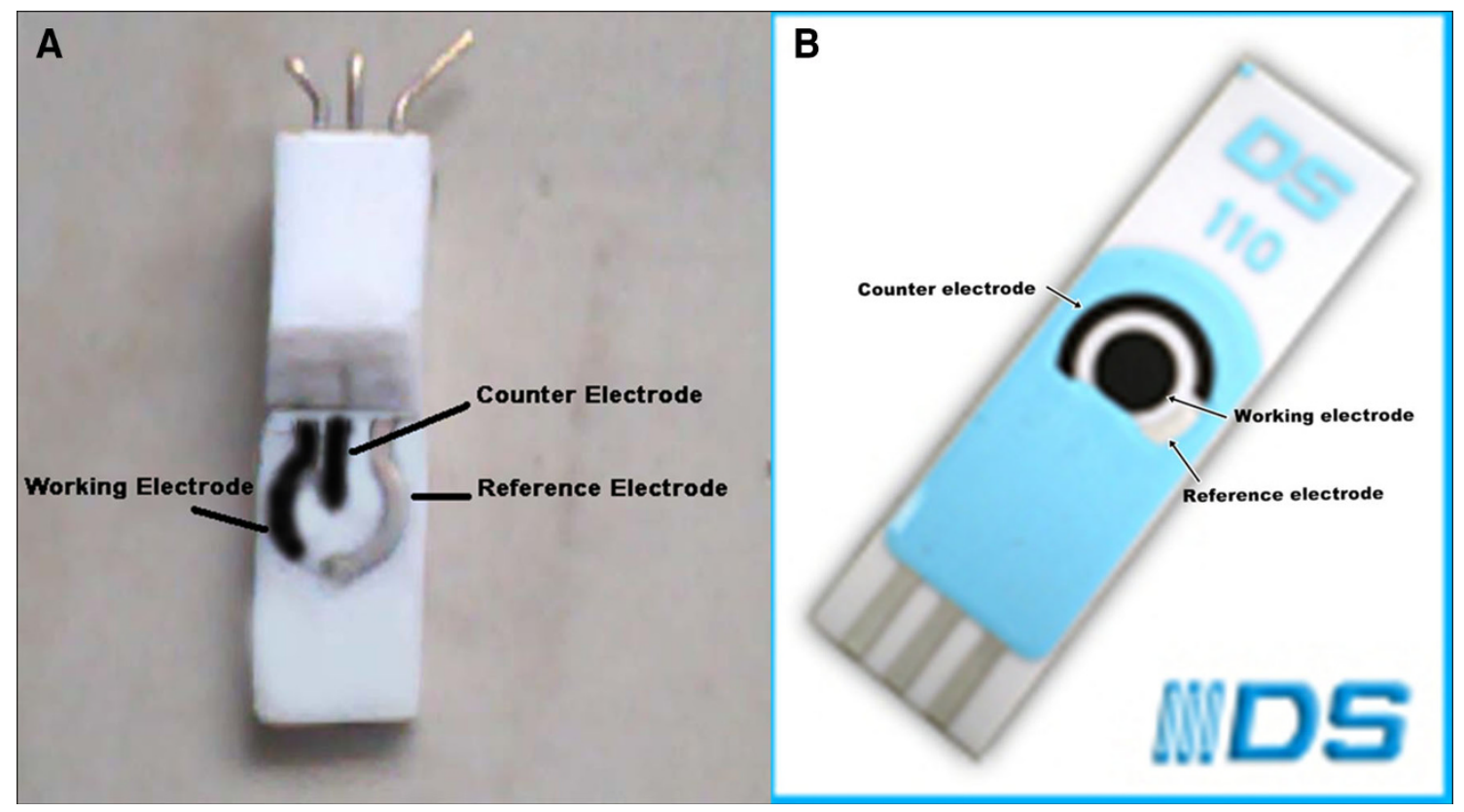

Fig. 1 a Image of carbon nanotube (CCNT) modified electrode. b Image of commercially available screen printed carbon nanotube electrode (DS110CNT)

\section{Results and discussions}

\section{Characterizations of CCNT}

The SEM micrograph of CCNT was shown in Fig. 1 which clearly shows the formation of the tubular structure CCNT having diameter below $100 \mathrm{~nm}$. Figure 2 shows the XRD patterns of CCNT. The XRD pattern indicated the presence of two predominant peaks at $25.2^{\circ}$ and $43.8^{\circ}$, which corresponds to (002) and (001) planes of CCNT, respectively. Raman spectra of CCNT, shown in Fig. 3, showed two prominent peaks at around 1350 and $1600 \mathrm{~cm}^{-1}$. The less intensed peak was known as D band and peak having more intensity was known as G band.

\section{Electrochemical characterization of CCNT electrode}

The active surface area of CCNT electrode was estimated by $\mathrm{CV}$ using $5 \times 10^{-4} \mathrm{M} \mathrm{K}_{4}\left[\mathrm{Fe}(\mathrm{CN})_{6}\right]$ in $0.1 \mathrm{M} \mathrm{H}_{2} \mathrm{SO}_{4}$ as a redox probe at various scan rate, by following RandlesSevcik equation (Eq. 1) [24].

$I_{\mathrm{P}}=\left(2.69 \times 10^{5}\right) n^{3 / 2} \mathrm{AD}^{1 / 2} C v^{1 / 2}$

where $n$ is the number of electrons participating in the redox reaction, $A$ is the electroactive surface area $\left(\mathrm{cm}^{2}\right)$, $D$ is the diffusion coefficient $\left(\mathrm{cm}^{2} \mathrm{~s}^{-1}\right), C$ is the concentration of the redox probe molecule $\left(\mathrm{mol} \mathrm{cm} \mathrm{cm}^{-3}\right)$, and $v$ is the scan rate $\left(\mathrm{mVs}^{-1}\right)$.

Furthermore, $I_{\mathrm{P}}$ increases with $v^{1 / 2}$ (Fig. 4) and is directly proportional to concentration and the ratio of
$I_{\mathrm{Pa}}-I_{\mathrm{Pc}}$ is close to one. The $\left[\mathrm{Fe}(\mathrm{CN})_{6}\right]^{3-} /^{4-}$ is one of the most extensively studied redox couples in electrochemistry, which exhibits a heterogeneous one electron transfer $(n=1)$.The calculated electroactive surface area of CCNT electrode was found to be $0.0765 \mathrm{~cm}^{2}$, where $C=10^{-4} \mathrm{M}$, $D=6.5 \times 10^{-6} \mathrm{~cm}^{2} / \mathrm{s}$ for $\left[\mathrm{Fe}(\mathrm{CN})_{6}\right]^{3-/ 4-}$ system.

Mechanism of nonenzymatic detection of cholesterol at CCNT electrode

For nonenzymatic detection of cholesterol, CV and DPV studies with various concentrations of cholesterol solutions were performed using $0.001 \mathrm{M} \mathrm{H}_{2} \mathrm{SO}_{4}$ as supporting electrolyte. CV and DPV plots clearly showed the presence of two peaks which suggests the generation of two electro active compounds during the reaction of cholesterol and $\mathrm{H}_{2} \mathrm{SO}_{4}$. The probable mechanism may be attributed to the fact that when cholesterol reacts with $\mathrm{H}_{2} \mathrm{SO}_{4}$, initially one product is formed which was unstable and therefore decomposed to another stable product in second step. This mechanism is also supported by Liebermann-Burchard method for cholesterol [25]. Therefore, the probable reaction may be represented as:

Cholesterol $+\mathrm{H}_{2} \mathrm{SO}_{4} \rightarrow$

bis - cholestadienyl monosulfonic acid

Bis - cholestadienyl monosulfonic acid $+\mathrm{H}_{2} \mathrm{SO}_{4}$

$\rightarrow$ bis - cholestadienyl disulfonic acid

From CV and DPV studies, it can be concluded that the low intensity of the peaks was due to the formation of 


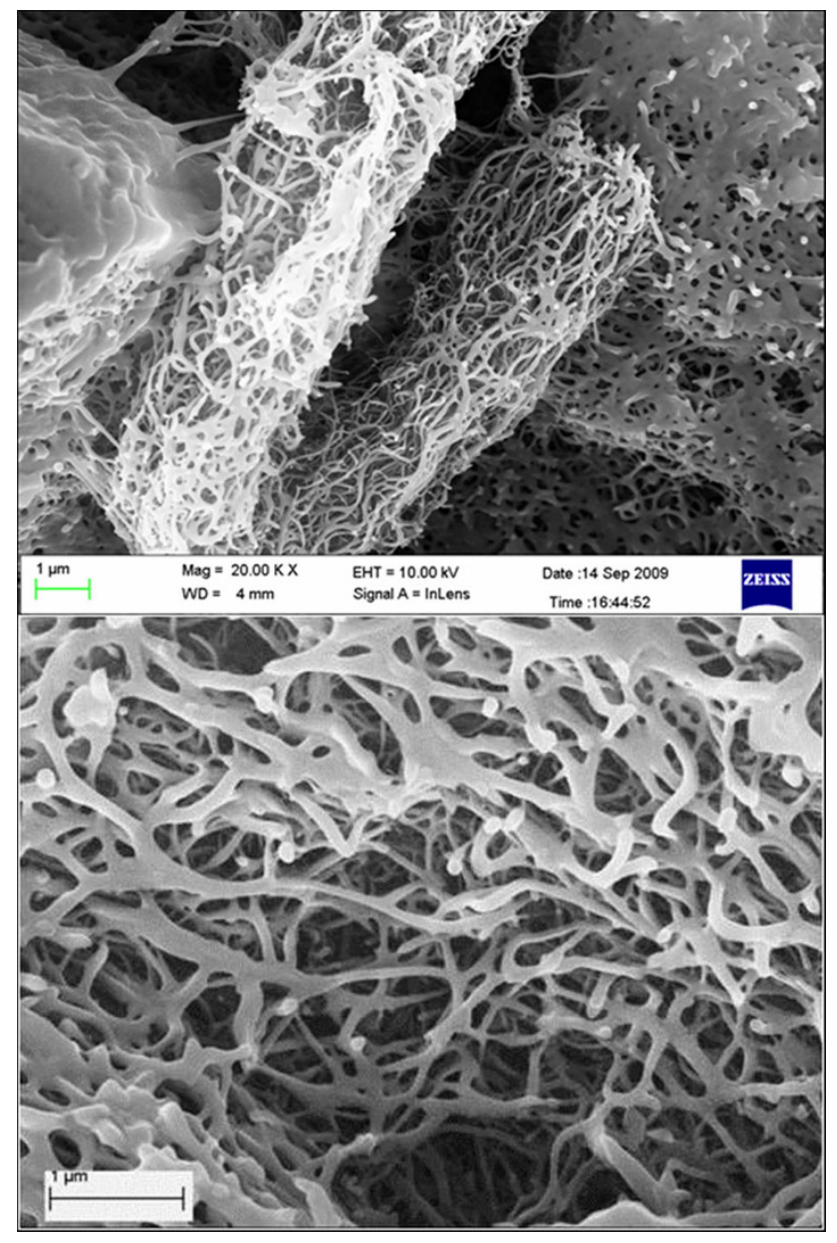

Fig. 2 SEM images of carbon nanotube (CCNT)

bis-cholestadienyl monosulfonic acid which decomposes to bis-cholestadienyl disulfonic acid resulting in a high intense peak.

Electrochemical response of cholesterol on different electrodes

The electrochemical behavior of $10^{-5} \mathrm{M}(10 \mu \mathrm{M})$ cholesterol in $0.001 \mathrm{M} \mathrm{H}_{2} \mathrm{SO}_{4}(\mathrm{pH} \sim 5.3)$ at a scan rate of $100 \mathrm{mVs}^{-1}$ on bare silver, standard screen printed carbon nanotube electrode (DS110CNT) and CCNT modified electrode was studied by CV. Figure 5 showed that for the first peak, the peak potentials on DS110CNT electrode and CCNT modified electrode were almost same, i.e., -0.27 and $-0.26 \mathrm{~V}$, respectively. No peak current was observed at bare silver electrode which indicated that it cannot undergo the reaction in this potential range but for the second peak, a little rise in the peak current was observed at-0.056 V. DS110CNT electrode and our CCNT electrode again showed very close proximity in the peak potential values for the second peak, i.e., -0.092 and
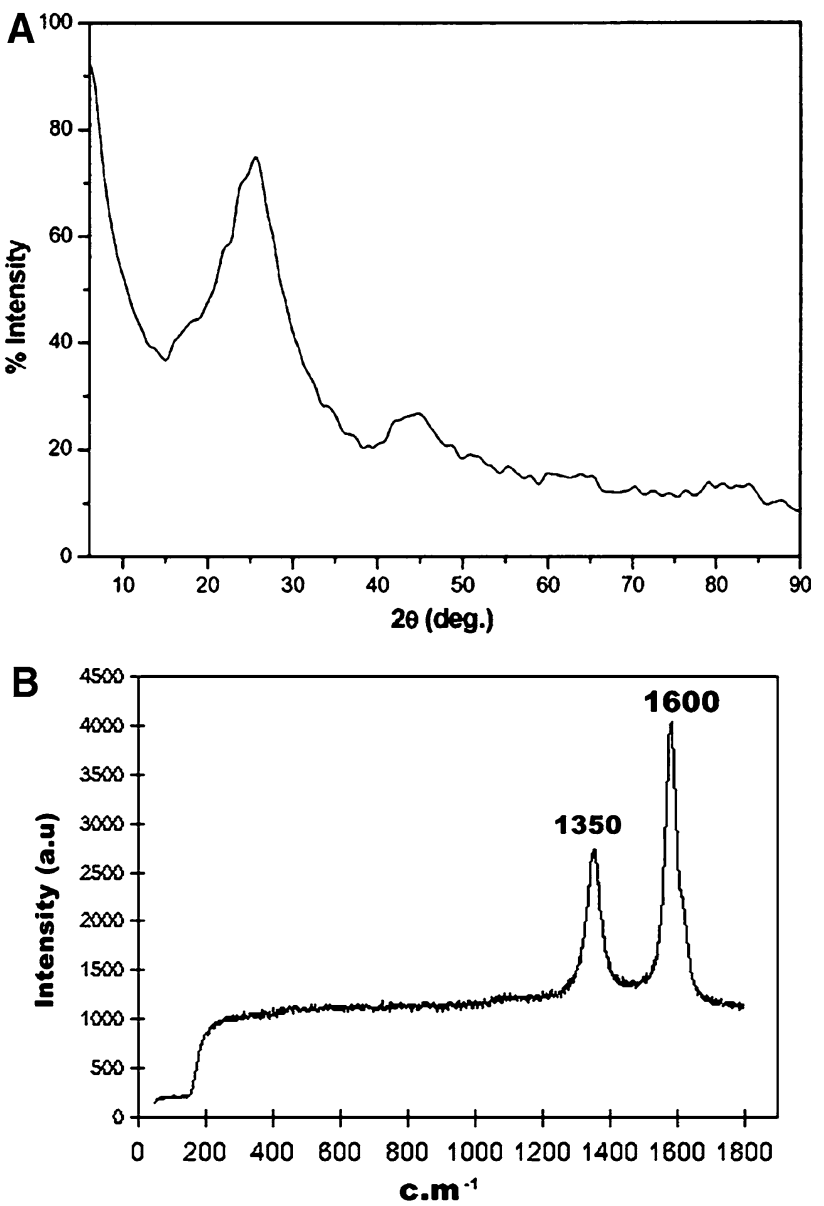

Fig. 3 a XRD pattern of carbon nanotube (CCNT). b Raman spectra of carbon nanotube (CCNT)

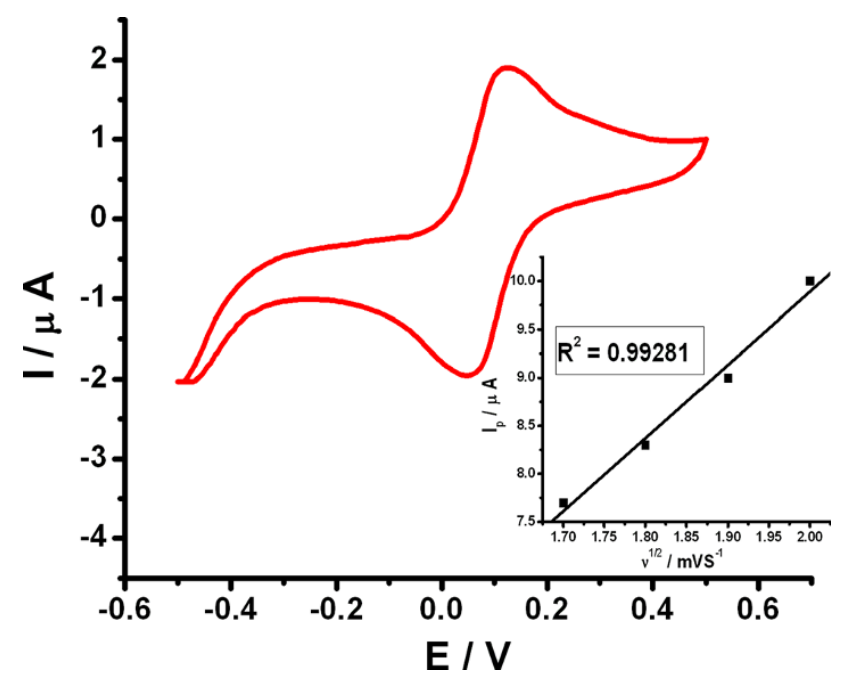

Fig. $4 \mathrm{CV}$ plot of $5 \times 10^{-4} \mathrm{M}\left[\mathrm{K}_{4} \mathrm{Fe}(\mathrm{CN})_{6}\right]$ in $0.1 \mathrm{M} \mathrm{H}_{2} \mathrm{SO}_{4}$ on CCNT electrode. Inset the plot of peak current $\left(I_{\mathrm{P}} / \mu \mathrm{A}\right)$ versus square root of scan rate $\left(v^{1 / 2} / \mathrm{mV} \mathrm{s}^{-1}\right)$

$0.003 \mathrm{~V}$, respectively. Although the peak potentials were in very good agreement with each other, but heights of the peaks were different for each electrode. The order of the 


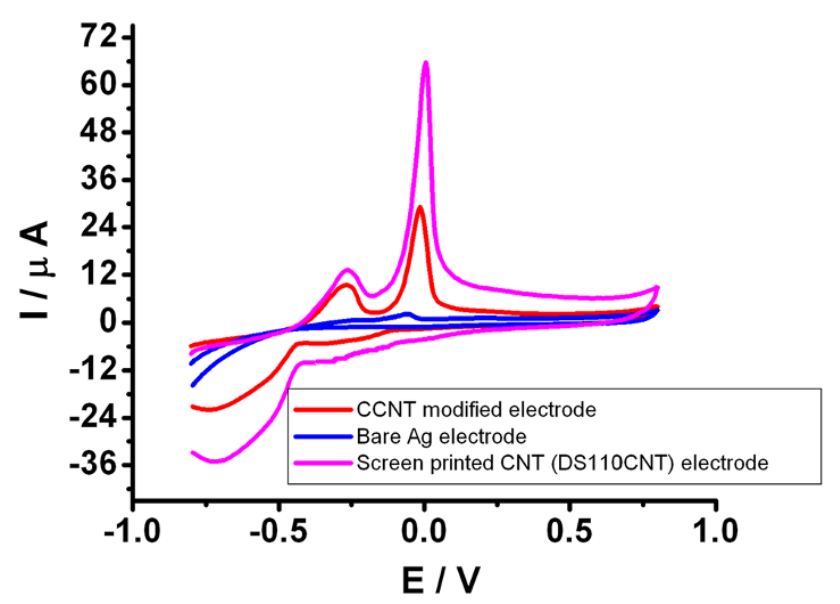

Fig. $5 \mathrm{CV}$ plots of $10^{-5} \mathrm{M}$ cholesterol in $0.001 \mathrm{M} \mathrm{H}_{2} \mathrm{SO}_{4}$ at $100 \mathrm{mV} \mathrm{s}^{-1}$ scan rates on bare Ag electrode, screen printed carbon electrode (DS110), and CCNT modified electrode at $\mathrm{pH} \sim 5.3$

heights of the peaks was found to be $I / \mu \mathrm{A}$ (DS110CNT electrode) $>I / \mu \mathrm{A}(\mathrm{CCNT}$ electrode $)>I / \mu \mathrm{A}$ (bare silver electrode). Thus, it may further be concluded that the unique shape and dimension of nanostructured CCNT electrode offered good electrical conductivity almost like standard CNT electrode, resulting in the increased peak current than bare silver electrode and almost same peak potential like DS110CNT electrode.

\section{Effect of $\mathrm{pH}$}

Figure 6a displayed the effect of different $\mathrm{pH}$ on the electrochemical response of $10^{-5} \mathrm{M}$ cholesterol in $0.001 \mathrm{M} \mathrm{H}_{2} \mathrm{SO}_{4}$ at a scan rate of $100 \mathrm{mVs}^{-1}$ at CCNT electrode. It was observed that when the $\mathrm{pH}$ changed from 4.7 to 6.7 , the anodic peak in $\mathrm{CV}$ moved towards the negative direction and the current response decreased. Figure $6 \mathrm{~b}$ showed the linear relationship between the anodic peak current and the $\mathrm{pH}$ value in the range of 5.3 and 6.7 following the equation $I / \mu \mathrm{A}=16.24791-$ $1.19302 \mathrm{pH}\left(R^{2}=-0.99636\right) . I / \mu \mathrm{A}$ vs. $\mathrm{pH}$ graph showed that for cholesterol, maximum peak current was observed at $\mathrm{pH} 5.3$ and hence this $\mathrm{pH}$ was chosen for the subsequent analytical experiments for cholesterol.

\section{Effect of scan rate}

$\mathrm{CV}$ technique was employed to find out the effect of the scan rate on the electrochemical detection of cholesterol at the CCNT electrode. Figure 7a displayed CV plots showing the overlapping of voltagrams of $10^{-5} \mathrm{M}$ cholesterol in $0.001 \mathrm{M} \mathrm{H}_{2} \mathrm{SO}_{4}(\mathrm{pH} \sim 5.3)$ at various scan rates on CCNT electrode. The current versus scan rate plot shown in the inset exhibited a linear relationship following the equation $I / \mu \mathrm{A}=6.28481+0.39227 \mathrm{v} / \mathrm{mV} \mathrm{s}^{-1}$, $R^{2}=0.99724$. This confirmed that the electrochemical kinetics reaction was adsorption-controlled [26] as the adsorption-controlled process should result in a linear plot in case of $I$ vs. $v$. The linearity was observed over the entire range $\left(50-112 \mathrm{mV} \mathrm{s}^{-1}\right)$ of scan rates studied with standard deviation value of 0.6189 , where $N=13$. A plot of logarithm of peak current vs. logarithm of scan rate gave a straight line with a slope of 1.2 (Fig. 7b) closed to the theoretical value of 1 for a purely adsorption-controlled process [24] which in turn further confirms that the process was adsorption-controlled. The linear regression equation $\log I / \mu \mathrm{A}=-1.00262+1.26127 \log v / \mathrm{mV} \mathrm{s}^{-1}$ gave the value $R^{2}=0.99811$.

In an adsorption-controlled system, the analyte does not have to travel to the electrode. Thus, when the potential required for reaction is reached, the current increases and decreases much more rapidly which results in a sharp peak with a high current density since all the analyte can react at once.

\section{Effect of accumulation time}

The effect of accumulation time on peak current was also investigated with $10^{-5} \mathrm{M}$ cholesterol in $0.001 \mathrm{M} \mathrm{H}_{2} \mathrm{SO}_{4}$ $(\mathrm{pH} \sim 5.3)$ at $\mathrm{CCNT}$ electrode. Figure 8 showed the plots of $\mathrm{CV}$ of $10^{-5} \mathrm{M}$ cholesterol in $0.001 \mathrm{M} \mathrm{H}_{2} \mathrm{SO}_{4}$ $(\mathrm{pH} \sim 5.3)$ at $100 \mathrm{mV} \mathrm{s}^{-1}$ scan rate and at various time
Fig. 6 a The effect of different $\mathrm{pH}$ on the electrochemical response of $10^{-5} \mathrm{M}$ cholesterol in $0.001 \mathrm{M} \mathrm{H}_{2} \mathrm{SO}_{4}$ at a scan rate of $100 \mathrm{mV} \mathrm{s}^{-1}$ at CCNT modified electrode. $\mathbf{b}$ The linear relationship between the anodic peak current and the $\mathrm{pH}$ value from 5.3 to 6.7
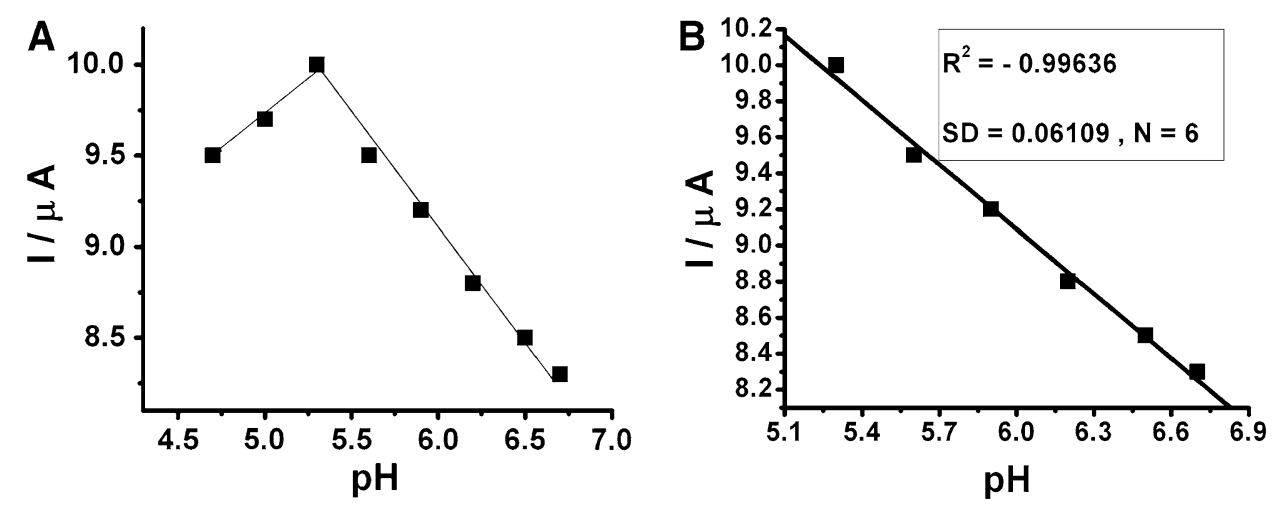


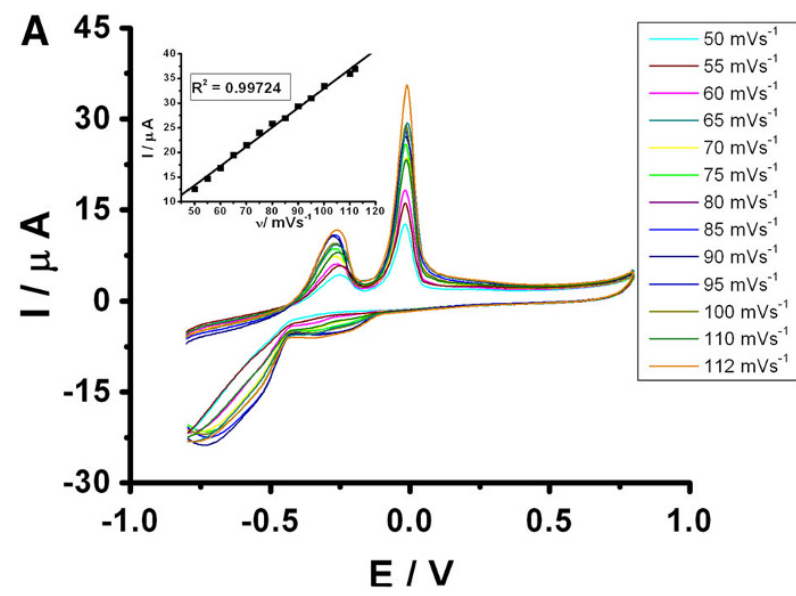

Fig. 7 a CVs of $10^{-5} \mathrm{M}$ cholesterol in $0.001 \mathrm{M} \mathrm{H}_{2} \mathrm{SO}_{4}$ at various scan rates $(50,55,60,65,70,75,80,85,90,95,100,110$, $112 \mathrm{mVs}^{-1}$ ) on CCNT modified electrode at $\mathrm{pH} \sim 5.3$. Inset: the

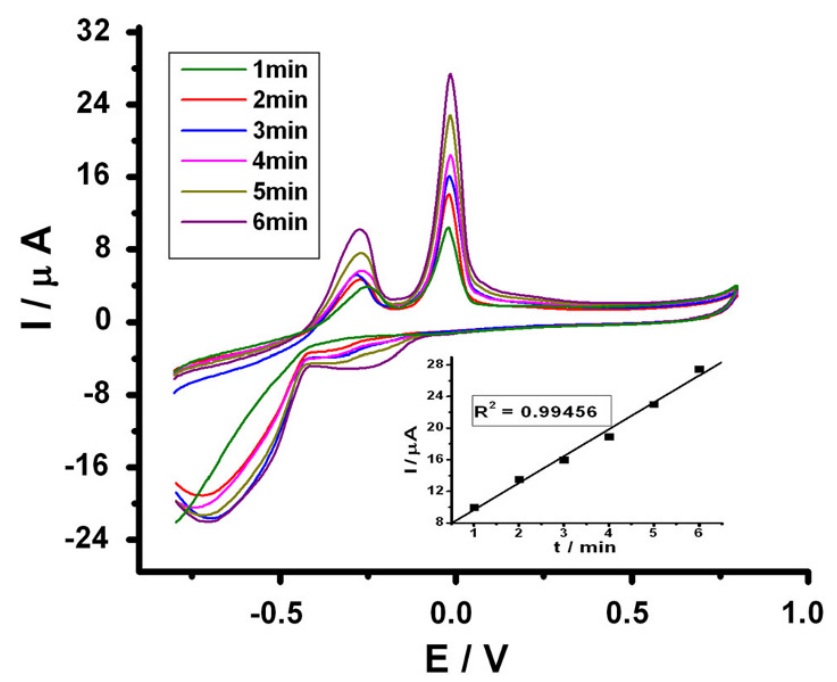

Fig. $8 \mathrm{CVs}$ of $10^{-5} \mathrm{M}$ cholesterol at CCNT modified electrode in $0.001 \mathrm{M} \mathrm{H}_{2} \mathrm{SO}_{4}$ in various time interval $(1,2,3,4,5,6 \mathrm{~min})$ at $100 \mathrm{mV} \mathrm{s}^{-1}$ scan rate at $\mathrm{pH} \sim 5.3$. Inset: the plot of peak current $(I / \mu \mathrm{A})$ versus time interval $(t / \mathrm{min})$

intervals (1-6 min). Calibration plot (in inset) showed a linear dependence of the anodic peak current on the entire range of time interval studied in the both cases giving the correlation coefficient of $0.99456(I / \mu \mathrm{A}=6.26+$ $3.39714 \mathrm{~min})[27,28]$. The standard deviation value was found to be 0.74412 , where $N=6$. However, if the study was conducted over a more extended time interval range then there was a breakdown in linearity relationship. This suggests that with the increase in accumulation time, the peak current increases gradually but after $6 \mathrm{~min}$ the peak current reached the maximum and becomes stable. Therefore, the optimal accumulation time of $6 \mathrm{~min}$ was employed in further experiments.
B

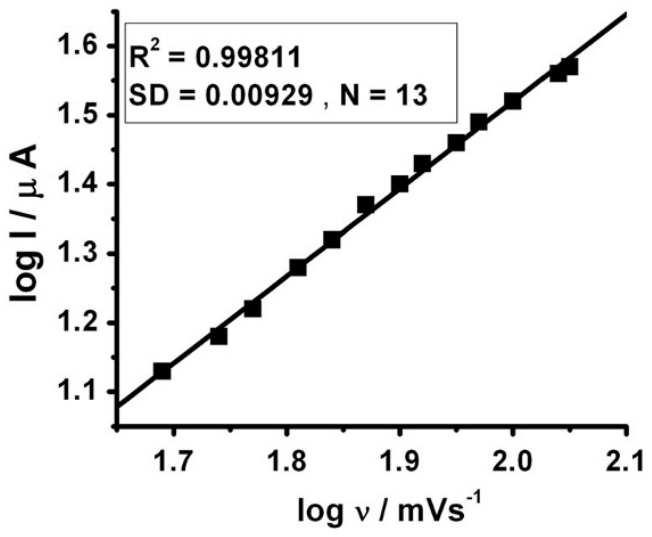

plot of peak current $(I / \mu \mathrm{A})$ versus scan rate $\left(v \mathrm{mV} \mathrm{s}^{-1}\right)$. b Linear relation between logarithm of peak current $(\log I / \mu \mathrm{A})$ and logarithm of scan rate $\left(\log v \mathrm{mV} \mathrm{s}^{-1}\right)$

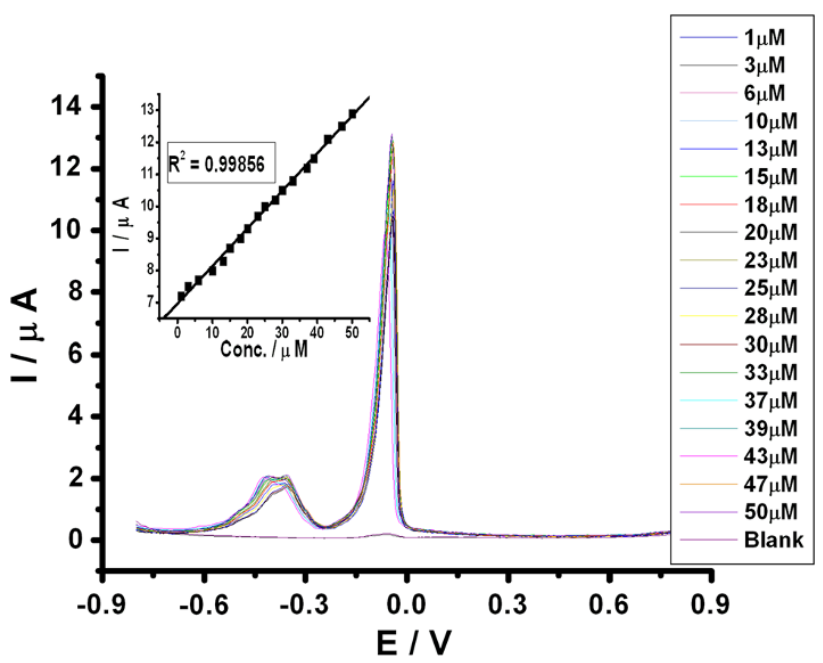

Fig. $9 \mathrm{CV}$ plots at CCNT modified electrode in $0.001 \mathrm{M} \mathrm{H}_{2} \mathrm{SO}_{4}$ with different concentrations of cholesterol $(0-50 \mu \mathrm{M})$ at $100 \mathrm{mV} \mathrm{s}^{-1}$ scan rate at $\mathrm{pH} \sim 5.3$. Inset: calibration curve of response current $(I / \mu \mathrm{A})$ versus concentrations of cholesterol (conc. $\mu \mathrm{M})$

Linearity, sensitivity, and limit of detection of the nonenzymatic cholesterol sensor

To determine the quantitative analysis of cholesterol at the CCNT electrode, DPV technique was employed because the peaks were sharper and better defined at lower concentration of cholesterol than those obtained by $\mathrm{CV}$ studies. $0.001 \mathrm{M} \mathrm{H}_{2} \mathrm{SO}_{4}(\mathrm{pH} \sim 5.3)$ was selected as the supporting electrolyte for the quantification of cholesterol as it gave maximum peak current intensity at $\mathrm{pH}=5.3$. Figure 9 showed that peak current increases linearly with the increasing concentration of cholesterol. A good linear relationship was observed between anodic current and 
cholesterol concentrations in the range of $1-50 \mu \mathrm{M}$. The linear regression equation $I \mu \mathrm{A}=6.96911+0.11713$ gave the $R^{2}$ value as 0.99856 . However, if the study was conducted with more concentrated solution then there was a breakdown in linearity relationship which may be attributed to adsorption of oxidized products of cholesterol on the electrode surface. The sensitivity was calculated using the slope of the current versus concentration calibration plot (Fig. 9, inset) divided by the active surface area of CCNT according to the following equation [29]:

Sensitivity $=$ slope of the plot/ active surface area of the electrode...

where the active surface area of CCNT was $0.0765 \mathrm{~cm}^{2}$ and the slope was $1.1713 \mu \mathrm{A} \mu \mathrm{M}^{-1}$. The sensitivity of the modified CCNT nonenzymatic cholesterol sensor was calculated to be $\sim 15.31 \pm 0.01 \mu \mathrm{A \mu M} \mathrm{M}^{-1} \mathrm{~cm}^{-2}$.

The limit of detection (LOD) and limit of quantification (LOQ) were calculated using the following equation:

LOD $=3 \mathrm{~s} / \mathrm{m} ; \mathrm{LOQ}=10 \mathrm{~s} / \mathrm{m}$, where $s$ is the standard deviation of the peak currents of the blank (five runs), and

Table 1 Characteristics of calibration plot of nonenzymatic cholesterol sensor using DPV at CCNT modified electrode

\begin{tabular}{ll}
\hline Linear range & $1-50 \mu \mathrm{M}$ \\
Correlation coefficient $\left(R^{2}\right)$ & 0.99856 \\
Standard deviation (SD) & 0.09749 \\
Slope of the calibration plot (m) & 1.1713 \\
Intercept & 6.96911 \\
Number of data points $(N)$ & 18 \\
Sensitivity & $\sim 15.31 \pm 0.01 \mu \mathrm{A} \mu \mathrm{M}^{-1} \mathrm{~cm}^{-2}$ \\
limit of detection (LOD) & $0.017 \mu \mathrm{M}$ \\
limit of quantification (LOQ) & $0.056 \mu \mathrm{M}$ \\
Reproducibility of peak current & $3.5 \%$ \\
$\quad$ RSD \%) & \\
\hline
\end{tabular}

$m$ is the slope of the calibration curve [30]. The values were found to be 0.017 and $0.056 \mu \mathrm{M}$, respectively. Statistical data of the calibration curve are obtained from five different determinations were shown in Table 1.

The detection limit, sensitivity, and response time of CCNT electrode was compared to that of other reported electrodes used for cholesterol sensors [8-13] and it was found that these results were in good agreement with literature values (Table 2).

Reproducibility and stability of the nonenzymatic cholesterol sensor

Reproducibility and stability are two important characteristics for the any modified electrode. The reproducibility of the proposed electrochemical sensor was evaluated by determining the voltammetric response of $10^{-5} \mathrm{M}$ cholesterol (five separate samples) in $0.001 \mathrm{M} \mathrm{H}_{2} \mathrm{SO}_{4}$ at the same $\mathrm{pH}$ at CCNT electrode (five times) by DPV studies. It was found that the average peak current was $12.5 \mu \mathrm{A}$, and the relative standard deviation (RSD) was $3.5 \%$ which showed acceptable reproducibility of the proposed cholesterol sensor (Table 3). The stability of the nonenzymatic cholesterol sensor was also explored by storing the modified electrode in air for 10 days and the current response of $10^{-5} \mathrm{M}$ cholesterol was found to be stable, keeping $\sim 97 \%$ of its initial intensity.

\section{Interference}

Under optimized experimental conditions mentioned above, some species can possibly interfere with cholesterol determination. So, the effects of the presence of some interfering substances on the current responses of $10^{-5} \mathrm{M}$ cholesterol have been evaluated by DPV studies to ensure the selectivity of the reported cholesterol biosensor. Voltammetric studies were carried out by analyzing the sample

Table 2 A comparison of CCNT electrode with other modified electrode, using as cholesterol sensor

\begin{tabular}{|c|c|c|c|c|}
\hline Electrode & Linear range & LOD & Sensitivity & $\begin{array}{l}\text { Response } \\
\text { time (s) }\end{array}$ \\
\hline Pt NP/(CNT)24 bilayer electrode [8] & $0.005-10 \mathrm{mM}$ & - & $8.7 \mu \mathrm{A} \mathrm{mM}{ }^{-1} \mathrm{~cm}^{-2}$ & - \\
\hline $\mathrm{ChEt}-\mathrm{ChOx} / \mathrm{MWCNT} / \mathrm{SiO}_{2}-\mathrm{CHIT} / \mathrm{ITO}$ [9] & $10-500 \mathrm{mg} / \mathrm{dL}$ & $16 \mathrm{mM}$ & $3.8 \mu \mathrm{A} / \mathrm{mM}$ & 10 \\
\hline ChOx/MWCNTs/GCE [10] & $0.0468-0.279 \mathrm{mM}$ & $46.8 \mathrm{mM}$ & - & - \\
\hline $\mathrm{PDDA} / \mathrm{ChOx} / \mathrm{MWNT} / \mathrm{Au} / / \mathrm{PPD}[11]$ & Up to $6.0 \mathrm{mM}$ & $0.2 \mathrm{mM}$ & - & - \\
\hline $\begin{array}{l}\text { COD/CEH/peroxidase/pot.ferrocyanide/ } \\
\text { MWCN [12] }\end{array}$ & $100-400 \mathrm{mg} / \mathrm{dL}$ & - & 0.0059 and $0.0032 \mu \mathrm{A} / \mathrm{mg} / \mathrm{dL}$ & - \\
\hline $\mathrm{GC} / \mathrm{PB} / \mathrm{CS}-\mathrm{SiO}_{2}$-COX-MWCNTs [13] & $4.0 \times 10^{-6}$ to $7.0 \times 10^{-4} \mathrm{M}$ & $1.0 \times 10^{-6} \mathrm{M}$ & $1.55 \mu \mathrm{A} \mathrm{mM}^{-1}$ & 13 \\
\hline CCNT modified electrode (this work) & $1-50 \mu \mathrm{M}$ & $0.01708 \mu \mathrm{M}$ & $\sim 15.31 \pm 0.01 \mu \mathrm{A} \mu \mathrm{M}^{-1} \mathrm{~cm}^{-2}$ & 6 \\
\hline
\end{tabular}

ChEt/CEH cholesterol esterase, ChOx/COD cholesterol oxidase, GCE/GC glassy carbon electrode, PDDA poly diallyl dimethyl ammonium chloride, $P P D$ poly (o-phenylenediamine), $M W C N T / M W N T / M W C N$ multiwalled carbon nanotube, $P B$ Prussian blue, PtNP platinum nano particle 
Table 3 Influence of interfering species on the voltammetric response of $10^{-5} \mathrm{M}$ cholesterol

\begin{tabular}{llll}
\hline $\begin{array}{l}\text { Cholesterol } \\
\left(10^{-5} \mathrm{M}\right)+\end{array}$ & $\begin{array}{l}\text { Observed } \\
\text { potential } \\
\text { interfering } \\
\text { species }\left(10^{-4} \mathrm{M}\right)\end{array}$ & $\begin{array}{l}\text { Signal } \\
\text { change } \\
(\%)\end{array}$ & $\begin{array}{l}\text { Average } \\
\text { signal } \\
\text { change }(\%)\end{array}$ \\
\hline Chl & $-0.357,-0.0153$ & 0 & \\
Chl + urea & $-0.353,-0.0151$ & $-1.12,-1.30$ & \\
Chl + uric acid & $-0.359,-0.0153$ & $0.56,0$ & \\
Chl + Vitamin-C & $-0.351,-0.0157$ & $-1.68,2.61$ & \\
Chl + L-alanine & $-0.356,-0.0159$ & $-0.28,0.06$ & \\
Chl + glycine & $-0.358,-0.0152$ & $0.28,-0.65$ & 1.364 \\
Chl + L-serine & $-0.357,-0.0155$ & $0,1.30$ & \\
Chl + & $-0.354,-0.0157$ & $-0.84,2.61$ & \\
L-phenylalanine & & & \\
Chl + tryptophan & $-0.352,-0.0154$ & $-1.4,0.65$ & \\
Chl + tyrosine & $-0.350,-0.0156$ & $-1.96,1.96$ & \\
Chl + glucose & $-0.347,-0.0161$ & $-2.80,5.22$ & \\
$\quad\left(5 \times 10^{-5} \mathrm{M}\right)$ & & & \\
\hline
\end{tabular}

Chl cholesterol

solutions of $10^{-5} \mathrm{M}$ cholesterol, spiked with various amount of urea, uric acid, glucose, vitamin $\mathrm{C}$, L-alanine, glycine, L-serine, L-phenylalanine, tryptophan, tyrosine under the same experimental conditions. The experimental results (Table 3) indicated that ten times of each substance and five times of glucose showed almost no interference with the determination of cholesterol. Hence, it can be further concluded that the proposed method was able to assay cholesterol in the presence of interfering substances also. The average signal change was found to be $1.364 \%$.

\section{Conclusions}

A nonenzymatic cholesterol biosensor has been fabricated at the surface of CCNT electrode. The most attractive features of this biosensor were mainly its selectivity and sensitivity. A higher producible sensitivity of $\sim 15.31 \pm 0.01 \mu \mathrm{A} \mu \mathrm{M}^{-1} \mathrm{~cm}^{-2}$, response time of $6 \mathrm{~s}$ and detection limit of $0.01708 \mu \mathrm{M}$ were obtained from the fabricated biosensor. The long-term storage stability of the sensor was tested for 10 days. The sensitivity retained $\sim 97 \%$ of initial sensitivity up to 10 days. However, the detailed studies of CCNT cholesterol biosensor for estimation of total cholesterol in serum and blood samples by nonenzymatic method, as well as the effect of various interfering substances with their increasing concentration, are in progress.

Acknowledgments The authors are thankful to AICTE, New Delhi for financial support and NEHU, Shillong for characterizations.
Conflict of interest The authors declare that they have no competing interests.

Author contributions SD has been involved in experimental works. SD have also made substantial contributions to the analysis and interpretation of data. SD and MS carried out the manuscript preparation. MS have given final approval of the version to be published.

Open Access This article is distributed under the terms of the Creative Commons Attribution License which permits any use, distribution, and reproduction in any medium, provided the original author(s) and the source are credited.

\section{References}

1. Norouzi, P., Faridbod, F., Nasli-Esfahani, E., Larijani, B., Ganjali, M.R.: Cholesterol biosensor based on MWCNTs- $\mathrm{MnO}_{2}$ nanoparticles using FFT continuous cyclic voltammetry. Int. J. Electrochem. Sci. 5, 1008-1017 (2010)

2. Aravamudhan, S., Ramgir, N.S., Bhansali, S.: Electrochemical biosensor for targeted detection in blood using aligned $\mathrm{Au}$ nanowires. Sens. Actuat. B 127, 29-35 (2007)

3. Arya, S.K., Solanki, P.R., Singh, S.P., Kaneto, K., Pandey, M.K., Datta, M., Malhotra, B.D.: Poly-(3-hexylthiophene) self-assembled monolayer based cholesterol biosensor using surface plasmon resonance technique. Biosens. Bioelectron. 22, 2516-2524 (2007)

4. Solanki, P.R., Kaushik, A., Agrawal, V.V., Malhotra, B.D.: Nanostructured metal oxide-based biosensors. NPG Asia Mater. 3, 17-24 (2011)

5. Manjunatha, R., Nagaraju, D.H., Suresh, G.S., Melo, J.S., Souza, S.F.D., Venkatesha, T.V.: Direct electrochemistry of cholesterol oxidase on MWCNTs. J. Electroanal. Chem. 651, 24-29 (2011)

6. Norouzi, P.: Application of coulometric FFT cyclic voltammetry for determination of cholesterol based on cholesterol oxidase nano-biosensor. Anal. Bioanal. Electrochem. 4(1), 70-82 (2010)

7. Sejin, P., Hankil, B., Taek, D.C.: Electrochemical non-enzymatic glucose sensors, review. Anal. Chim. Acta. 556, 46-57 (2006)

8. Yang, J., Lee, H., Cho, M., Nam, J., Lee, Y.: Non enzymatic cholesterol sensor based on spontaneous deposition of platinum nanoparticles on layer-by-layer assembled CNT thin film. Sens. Actuat. B Chem. 171, 374-379 (2012)

9. Solanki, P.R., Kaushik, A., Ansari, A.A., Tiwari, A., Malhotra, B.D.: Multi-walled carbon nanotubes/sol-gel-derived silica/ chitosan nanobiocomposite for total cholesterol sensor. Sens. Actuat. B 137, 727-735 (2009)

10. Yang, J.Y., Li, Y., Chen, S.M., Kuo, C.L.: Fabrication of a cholesterol biosensor based on cholesterol oxidase and multiwall carbon nanotube hybrid composites. Int. J. Electrochem. Sci. 6, 2223-2234 (2011)

11. Guo, M., Chen, J., Li, J., Lihua, N., Shouzhuo, Y.: Carbon nanotubes-based amperometric cholesterol biosensor fabricated through layer-by-layer technique. Electroanalysis 16, 1992-1998 (2004)

12. Li, G., Liao, J.M., Hu, G.Q., Ma, N.Z., Wu, P.J.: Study of carbon nanotube modified biosensor for monitoring total cholesterol in blood. Biosens. Bioelectron. 20, 2140-2144 (2005)

13. Tan, X., Li, M., Cai, P., Lijun, L., Xiaoyong, Z.: An amperometric cholesterol biosensor based on multiwalled carbon nanotubes and organically modified sol-gel/chitosan hybrid composite film. Anal. Biochem. 337, 111-120 (2005)

14. Soylemez, S., Fulya, E.K., Ayda, G.N., Hava, A., Levent, T.: A novel conducting copolymer: investigation of its matrix 
properties for cholesterol biosensor applications. Sens. Actuat. B Chem. 182, 322-329 (2013)

15. Sunil, K.A., Monika, D., Bansi, D.M.: Recent advances in cholesterol biosensor. Biosens. Bioelectron. 23, 1083-1100 (2008)

16. Soylemeza, S., Fulya, E.K., Simge, T., Yasemin, A.U., Levent, T.: A sepiolite modified conducting polymer based biosensor. Colloids Surf. B 112, 549-555 (2013)

17. Soylemez, S., Fulya, E.K., Merve, I., Serife, O.H., Levent, T.: Development of a novel biosensor based on a conducting polymer. Talanta 118, 84-89 (2014)

18. Mitali, S., Soma, D.: Electrochemical studies of carbon nanotube obtained from coconut oil as non enzymatic glucose biosensor. Adv. Sci. Eng. Med. 5, 645-648 (2013)

19. Soma, D., Mitali, S.: Non enzymatic electrochemical detection of glucose at rice starch-nanoparticles modified electrode. Int. J. Pharm. Bio. Sci. 4, 967-975 (2013)

20. Soma, D., Mitali, S.: Preparation of carbon nanosphere from bamboo and its use in water purification. Curr. Trends Tech. Sci. 2, 174-177 (2013)

21. Sumit, K.S., Manav, S., Mitali, S., Sabyasachi, S.: Carbon nanocubes and nanobricks from pyrolysis of rice. J. Nanosc. Nanotech. 10, 1-4 (2010)

22. Monica, D., Soma, D., Mitali, S.: Effect of reducing agents on the structure of zinc oxide under microwave irradiation. Adv. Manuf. 1, 183-186 (2013)
23. Heines, V.: Peter Griess discoverer of diazo compounds. J. Chem. Educ. 35, 187-191 (1958)

24. Bard, A.J., Faulkner, L.R.: Electrochemical Methods-Fundamentals and Applications. Wiley, New York (2000)

25. Thomas, E.H., Harry, L.P.: Kinetics of the cholesterol-sulfuric acid reaction: a fast kinetic method for serum cholesterol. Clin. Chem. 19(10), 1128-1134 (1973)

26. Jr Gosser, D.K.: Cyclic Voltammetry: Simulation and Analysis of Reaction Mechanisms. Wiley-VCH, NewYork (1993)

27. Lin, Y., Lu, F., Tu, Y., Ren, Z.: Glucose biosensors based on carbon nanotube nanoelectrode ensembles. Nano. Lett. 4, 191-195 (2004)

28. Wang, H., Zhou, C., Liang, J., Yu, H., Peng, F., Yang, J.: High sensitivity glucose biosensor based on pt electrode position onto low-density aligned carbon nanotubes. Int. J. Electrochem. Sci. 3, 1258-1267 (2008)

29. Dar, G.N., Umar, A., Zaidi, S.A., Ibrahim, A.A., Abaker, M., Baskoutas, S., Al-Assir, M.S.: Ce doped $\mathrm{ZnO}$ nanorods for the detection of hazardous chemical. Sens. Actuat. B Chem. 173, 72-75 (2012)

30. Swartz, E., Krull, I.S.: Analytical method development and validation. Marcel Dekkar, New York (1997) 